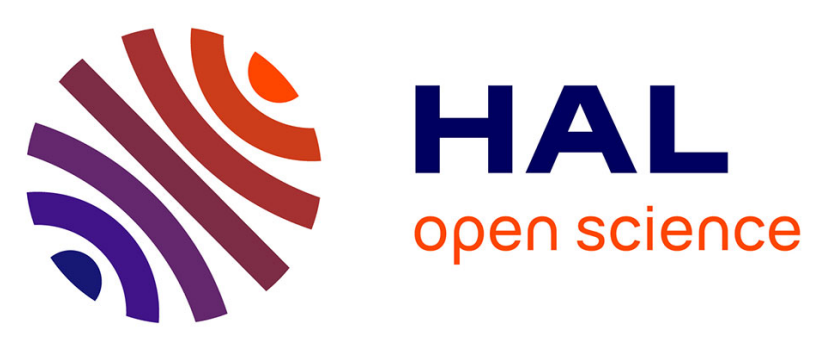

\title{
Beneficial Effects of Myocardial Postconditioning are Associated With Reduced Oxidative Stress in a Senescent Mouse Model
}

Benjamin Lauzier, Stéphanie Delemasure, Régine Debin, Bertrand Collin, Pierre Sicard, Niyazi Acar, Lionel Brétillon, Corinne Joffre, Alain Marie Bron, Catherine Creuzot-garcher, et al.

\section{To cite this version:}

Benjamin Lauzier, Stéphanie Delemasure, Régine Debin, Bertrand Collin, Pierre Sicard, et al.. Beneficial Effects of Myocardial Postconditioning are Associated With Reduced Oxidative Stress in a Senescent Mouse Model. Transplantation, 2008, 85 (12), pp.1802 - 1808. 10.1097/tp.0b013e3181775367. hal-03437195

\section{HAL Id: hal-03437195 \\ https://u-bourgogne.hal.science/hal-03437195}

Submitted on 19 Nov 2021

HAL is a multi-disciplinary open access archive for the deposit and dissemination of scientific research documents, whether they are published or not. The documents may come from teaching and research institutions in France or abroad, or from public or private research centers.
L'archive ouverte pluridisciplinaire HAL, est destinée au dépôt et à la diffusion de documents scientifiques de niveau recherche, publiés ou non, émanant des établissements d'enseignement et de recherche français ou étrangers, des laboratoires publics ou privés. 


\title{
Beneficial Effects of Myocardial Postconditioning are Associated With Reduced Oxidative Stress in a Senescent Mouse Model
}

\author{
Benjamin Lauzier, ${ }^{1,4}$ Stéphanie Delemasure, ${ }^{1}$ Régine Debin,${ }^{1}$ Bertrand Collin, ${ }^{1}$ Pierre Sicard, ${ }^{1}$ \\ Niyazi Acar, ${ }^{2}$ Lionel Bretillon, ${ }^{2}$ Corinne Joffre, ${ }^{2}$ Alain Bron, ${ }^{2,3}$ Catherine Creuzot-Garcher, ${ }^{2,3}$ \\ Catherine Vergely, ${ }^{1}$ and Luc Rochette ${ }^{1}$
}

\begin{abstract}
Background. There is at present a tragic lack of organs available for transplantation. This has led to the harvesting of hearts from older donors. Unfortunately, hearts from such donors are much more sensitive to ischemic insult. Models such as "Senescence Accelerated Mouse" Prone 8 (SAM-P8) can help understand this sensitivity. New cardioprotective techniques such as postconditioning (PostC) could be of interest in this context. We studied (1) senescence in vessels and hearts and (2) the ability of the senescent heart to adapt to an ischemia-reperfusion (I/R) sequence in the context of PostC.

Methods. Isolated working mouse hearts ( 8 months) were subjected to total ischemia, followed by 36 min of reperfusion; PostC was performed in the first minutes of reperfusion as three 10 -sec sequences of I/R. Superoxide anion $\left(\mathrm{O}_{2}{ }^{-{ }^{-}}\right)$ production was evaluated on heart and aorta cryosections with the dihydroethidium staining method. The collagen content in aortas was quantified.

Results. The aortas of SAM-P8 mice showed a higher production of $\mathrm{O}_{2}{ }^{--}$and a higher collagen content than did those of SAM-R1 mice $(P<0.05)$. During reperfusion, SAM-P8 hearts showed the worst recovery of cardiac output. PostC significantly reduced reperfusion dysfunction $(P<0.05)$ and was associated with a reduction in heart $\mathrm{O}_{2}{ }^{--}$staining. Conclusions. These results indicate that SAM-P8 presents a high degree of cardiovascular oxidative stress and a higher susceptibility to I/R injury, which confirms the senescence of the cardiovascular system in these animals. However, they remain sensitive to cardioprotection afforded by in vitro PostC.
\end{abstract}

Keywords: Postconditioning, Isolated working mouse heart, Senescence, Oxidative stress.

(Transplantation 2008;85: 1802-1808)

$I^{t}$

$\mathrm{t}$ is well documented that age is one of the most important prognostic indicators for cardiovascular disease and that senescent hearts present greater susceptibility to ischemic insult (1). Currently, there is a tragic lack of heart donors, which has led to the harvesting of hearts from older donors. However, hearts from such donors are much more sensitive to ischemic insult. Age is associated with a reduction in vascular elasticity (2), a reduction in the ability of the heart to adapt to stress (3), and with an increase in sensitivity to oxidative stress (4). With the aging of the population, it is of great importance to identify and to understand the mechanisms that lead to such intolerance to treat and protect the hearts of aged patients.

In recent years, animal models have been used more and more to delineate the pathophysiology of various diseases thanks to the development of genetically modified mice. Because mice are easy to breed and to handle, the use of the mouse model is increasing. The Senescence Accelerated Mouse Prone 8 (SAMP8) strain is an experimental murine model of spontaneous ac-

\footnotetext{
The authors declare no conflict of interest.

${ }^{1}$ Laboratoire de Physiopathologie et Pharmacologie Cardiovasculaires Expérimentales, Facultés de Médecine et Pharmacie, Dijon cedex, France.

${ }^{2}$ UMR1129 FLAVIC, INRA, ENESAD, Université de Bourgogne, Dijon cedex, France.

${ }^{3}$ Department of Ophthalmology, University Hospital, Dijon, France.

${ }^{4}$ Address correspondence to: Benjamin Lauzier, Ph.D., 7 bd Jeanne d'Arc, BP 87900, 21079 Dijon cedex, France.

E-mail: benjaminlauzier@yahoo.fr

Received 11 January 2008. Revision requested 1 February 2008.

Accepted 19 March 2008.

Copyright (C) 2008 by Lippincott Williams \& Wilkins

ISSN 0041-1337/08/8512-1802
}

DOI: $10.1097 /$ TP.0b013e3181775367 celerated aging (5). It has a lifespan of 10 months, compared with 20 months for its control the SAM-R1 strain (6). SAM-P8 is known to have an age-related deterioration in learning ability, neuronal dysfunction, insulin impaired sensitivity (7), and mitochondrial dysfunction (8). This strain shows a high level of oxidative stress in the brain (9) associated with lower neuroprotection. One theory hypothesizes that accelerated senescence in the brain could stem from oxidative stress because of excess production of reactive oxygen and nitrogen species. However, little is known about the cardiovascular status of this senescenceaccelerated mouse.

The postconditioning (PostC) protocol has been described in standard conditions as a way to reduce infarct size (10) and reperfusion arrhythmias (11), and to improve myocardial performance (12). Experimental studies on the restoration of myocardial function during the reperfusion of ischemic hearts have suggested that the beneficial effects of preconditioning (PreC) may be reduced by aging (13). Human data also report that PreC has a limited cardioprotective effect in the elderly (14). However, these conclusions are not universally accepted and it has been reported that PostC phenomena do not seem to decrease with aging (15). The effect of aging on the PostC response may thus be related to factors such as genetic strain and diseased myocardium. Recently, Iliodromitis et al. (16) showed that PostC was ineffective in limiting the infarct size in rabbits fed with a high cholesterol diet. It is now important to explore the physiopathological conditions $(17,18)$ to determine whether PostC is a good way to protect the heart in the field of cardiac transplantation in the elderly, in particular, from the deleterious consequences of reactive 
oxygen species produced during reperfusion. The present study has been designed to evaluate (1) the overall cardiovascular aging status of these senescence-accelerated mice, (2) the ability of the heart to adapt to an ischemia-reperfusion (I/R) sequence, and (3) the putative beneficial effects of PostC in this context. And here, we report that the benefits of PostC do not seem to be lost with aging in this strain of mice.

\section{MATERIALS AND METHODS}

\section{Animals}

The local ethics committee approved the experimental protocol and the investigators complied with authorization 5605 from the French government, which agrees with the Guide of the Care and use of Laboratory Animals published by US National Institutes for Health. The investigation conforms with the Guide for the Care and Use of Laboratory Animals published by the US National Institutes of Health (NIH Publication No. 85-23, revised 1996). Progenitors of the SAM-P8 and SAM-R1 strains, initially provided by the SAM Council (Kyoto University, Japan), were mated and bred at INRA Research Center (Dijon, France). Eight-month-old mice were anesthetized with sodium thiopental $(60 \mathrm{mg} / \mathrm{kg})$, and heparin (500 UI/kg) was injected intraperitoneally. The hearts were isolated and perfused, and abdominal aorta were excised and immediately frozen in optimum cutting temperature Tissue-Tek (Labonord, France) embedding medium and stored at $-80^{\circ} \mathrm{C}$.

\section{Functional Parameters}

\section{Working Heart Model}

The excised hearts were placed in a cold $\left(4^{\circ} \mathrm{C}\right)$ perfusion buffer bath until contractions ceased. They were cannulated using an $18 \mathrm{G}$ cannula and retrograde perfusion (Langendorff mode) was immediately initiated with warmed perfusion buffer at a constant hydrostatic pressure of $55 \mathrm{~mm} \mathrm{Hg}$. The hearts resumed beating almost immediately on rewarming. The total time from excision of the hearts to initiation of Langendorff perfusion did not exceed $3 \mathrm{~min}$. While in the Langendorff mode, a pulmonary vein was carefully dissected free and a cannula (PE-50) was passed through it into the left ventricle and pulled through the ventricular wall. It was then connected to a pressure transducer by a fluid-filled line. The left atrium was then cannulated with an $18 \mathrm{G}$ cannula through the same pulmonary vein, and then the pulmonary veins were collectively ligated around the cannula.

\section{Perfusion Medium}

The perfusion buffer consisted of a modified KrebsHenseleit bicarbonate buffer (millimolar concentrations: $\mathrm{NaCl} 118, \mathrm{NaHCO}_{3} 25, \mathrm{KH}_{2} \mathrm{PO}_{4} 1.2, \mathrm{MgSO}_{4} 1.2, \mathrm{KCl}$ 4.5, glucose $11, \mathrm{CaCl}_{2} 2$ ). The perfusion fluid was filtered through a $0.45 \mu \mathrm{M}$ Millipore to remove any particulate contaminants and gassed with $95 \%$ oxygen and $5 \%$ carbon dioxide $(\mathrm{pH}$ $7.3-7.4$ at $37^{\circ} \mathrm{C}$ ). Software developed in the laboratory was used to assess left ventricular end-diastolic pressure and left ventricular end-systolic pressure. The left ventricular developed pressure (left ventricular end-systolic pressure-left ventricular end-diastolic pressure) and heart rate (HR) were then calculated by the software. Coronary flow $(\mathrm{CF})$ and aortic flow $(\mathrm{AF})$ were measured by the timed collection of the effluent; cardiac output $(\mathrm{CO})$ was calculated as $(\mathrm{CO}=\mathrm{AF}+\mathrm{CF})$.

\section{Perfusion Protocols}

As shown in Figure 1, after a stabilization period of 10 min, the isolated hearts from SAM-P8 $(n=17)$ and SAM-R1 $(n=15)$ mice were perfused for $5 \mathrm{~min}$ in the Langendorff mode before $10 \mathrm{~min}$ of the working heart mode at $38^{\circ} \mathrm{C}$; cardiac parameters were recorded and used as preischemic values. After $20 \mathrm{~min}$ of total warm ischemia $\left(38^{\circ} \mathrm{C}\right)$ the SAM-P8 hearts and the SAM-R1 hearts were each randomized into two groups, one control and one PostC. PostC was applied to SAM-P8 $(n=8)$ and SAM-R1 $(n=7)$ mice at the onset of the aforementioned reperfusion sequence, it consisted of three cycles of $10 \mathrm{sec}$ of ischemia and $10 \mathrm{sec}$ of reperfusion. At the end of the protocol, the hearts were freeze clamped and stored at $-80^{\circ} \mathrm{C}$ for further analysis.

\section{Biochemical Parameters}

\section{In Situ Detection of Superoxide in Hearts After the} Ischemia-Reperfusion Sequence and in Aortas

Dihydroethidium (DHE), an oxidative fluorescent probe, was used to localize $\mathrm{O}_{2}{ }^{-}$according to the method modified in our laboratory (19).

\section{In Situ Detection of Collagen and Lipid Infiltration in Aortas}

As described previously (20), collagen content was assessed on cryosections using two different methods. In the first method, all sections were stained with hematoxylin, eosin, and Masson trichrome, the presence of collagen was scored at $\times 400$ magnification ( 0 , absence; 1 , mild; 2 , moderate; and 3 , marked). Three entire sectional areas were evaluated per artery, by two blinded investigators. For the second method, Picrosirius stained sections were observed under polarized light and captured with the same threshold for all specimens. Automatic computer-based analysis was performed with the same threshold for all specimens (Nikon Eclipse 600, Japan). The results are expressed as the percentage of collagen content per unit area.

Oil Red O (Sigma, France) staining was performed on cryosections that were incubated in 60\% isopropanol (Pro-

\begin{tabular}{|c|c|c|c|}
\hline \multicolumn{2}{|c|}{ Pre-ischemic perdiod } & \multicolumn{2}{|c|}{ Reperfusion } \\
\hline $\mathrm{L}: 5 \mathrm{~min}$ & $\mathrm{~W}: 10 \mathrm{~min}$ & $20 \mathrm{~min}$ at $38^{\circ} \mathrm{C}: 6 \mathrm{~min}$ & $\mathrm{~W}^{\prime}: 30 \mathrm{~min}$ \\
\hline
\end{tabular}

FIGURE 1. Perfusion protocols: after $15 \mathrm{~min}$ of baseline perfusion, the hearts were subjected to 20 min of warm ischemia $\left(38^{\circ} \mathrm{C}\right)$ followed by $36 \mathrm{~min}$ of reperfusion. $\mathrm{L}$ and $\mathrm{L}^{\prime}$ are the Langendorff perfusion periods, $\mathrm{W}$ and $\mathrm{W}^{\prime}$ are the working heart perfusion periods, PostC: postconditioning applied as 3 sequences of $10 \mathrm{sec}$ reperfusion and $10 \mathrm{sec}$ ischemia. 
labo, France) for $2 \mathrm{~min}$ and then in Oil Red O solution for 20 min and rinsed in $\mathrm{H}_{2} \mathrm{O}$. The presence of intracellular lipid droplets was scored at $\times 400$ magnification (yes/no score). Three entire sections were evaluated per artery, by two blinded investigators.

\section{Statistical Analysis}

All data are expressed as means \pm SEM. Statistical analyses were performed with the two-factor analysis of variance test (SigmaStat). Analysis of variance was followed by intergroup pair wise comparisons with Tukey HSD multiple comparisons. For histology, statistical analyses were performed with a nonparametric Mann-Whitney rank sum test (SigmaStat). Significance was established at a value of $P$ less than 0.05 .

\section{RESULTS \\ Vascular ageing status of SAM-P8}

\section{In Situ Detection of Superoxide in Aortas}

Dihydroethidium reacts with superoxide radicals to form ethidium bromide that intercalates with DNA to provide nuclear fluorescence. As illustrated in Figure 2(B and C), DHE staining in the vascular cells of SAM-P8 aortas was far more intense than that in the SAM-R1 group (20 times higher in SAM-P8 vs. SAM-R1; $P<0.001$, Fig. $2 A$ ).

\section{Collagen Content and Lipid Infiltration in Aortas}

The collagen content was evaluated on abdominal aorta cryosections by two methods; Figure 3(A), Masson trichrome staining, and Figure 3(B), picrosirius coloration. The results of both methods were comparable and showed a higher collagen content in SAM-P8 aortas than in SAM-R1; $1.13 \pm 0.05$ versus $1.41 \pm 0.07 \mathrm{AU} ; P$ less than 0.05 with de Masson trichrome staining; and $3.44 \pm 0.58$ versus $7.83 \pm 1.59$ AU; $P$ less than 0.05 for the picrosirius coloration.

Oil red O staining made it possible to evaluate lipid infiltration into the media of abdominal aortas, the yes/no score attributed to the aorta slices showed greater lipid infiltration into SAM-P8 aortas (3 times higher in SAM-P8 vs. SAM-R1; $P<0.05$ ) (Fig. 4 ).

\section{Evolution of Functional Parameters in SAM-P8 and SAM-RI Mice During Preischemia and Reperfusion Periods}

\section{Preischemic Period}

During the initial period, the HRs of the senescent hearts (SAM-P8) were significantly lower than those of the SAM-R1 group $(375 \pm 13$ vs. $333 \pm 12 \mathrm{bpm} ; P<0.05)$. However, the other parameters were similar (Table 1 ).

\section{Reperfusion Period and Postconditioning Effects}

To compare SAM-P8 and SAM-R1 groups, the results during the postischemic period are expressed as percentages of the preischemic values.

\section{Left Ventricular Developed Pressure}

Figure 5(A) shows results for the left ventricular developed pressure at the end of reperfusion. All hearts of the different groups recovered more than $60 \%$ of their preischemic value. SAM-P8 tended to develop lower values:
FIGURE 2. Quantification of superoxidedependent DHE fluorescence in frozen slices of aorta. Values are means $\pm \mathrm{SEM} * P$ less than $0.05 ; * * * P$ less than 0.001 . Fluorescence photomicrographs (magnification $\times 400$ ) with dihydroethidium (DHE) showing in situ detection of superoxide in the B: SAM-Rl and C: SAM-P8 aorta. Ethidium nuclear staining was considerably less intense in the SAM-R1 group than that observed in the SAM-P8 group. Figures are representative of at least six experiments in each group.
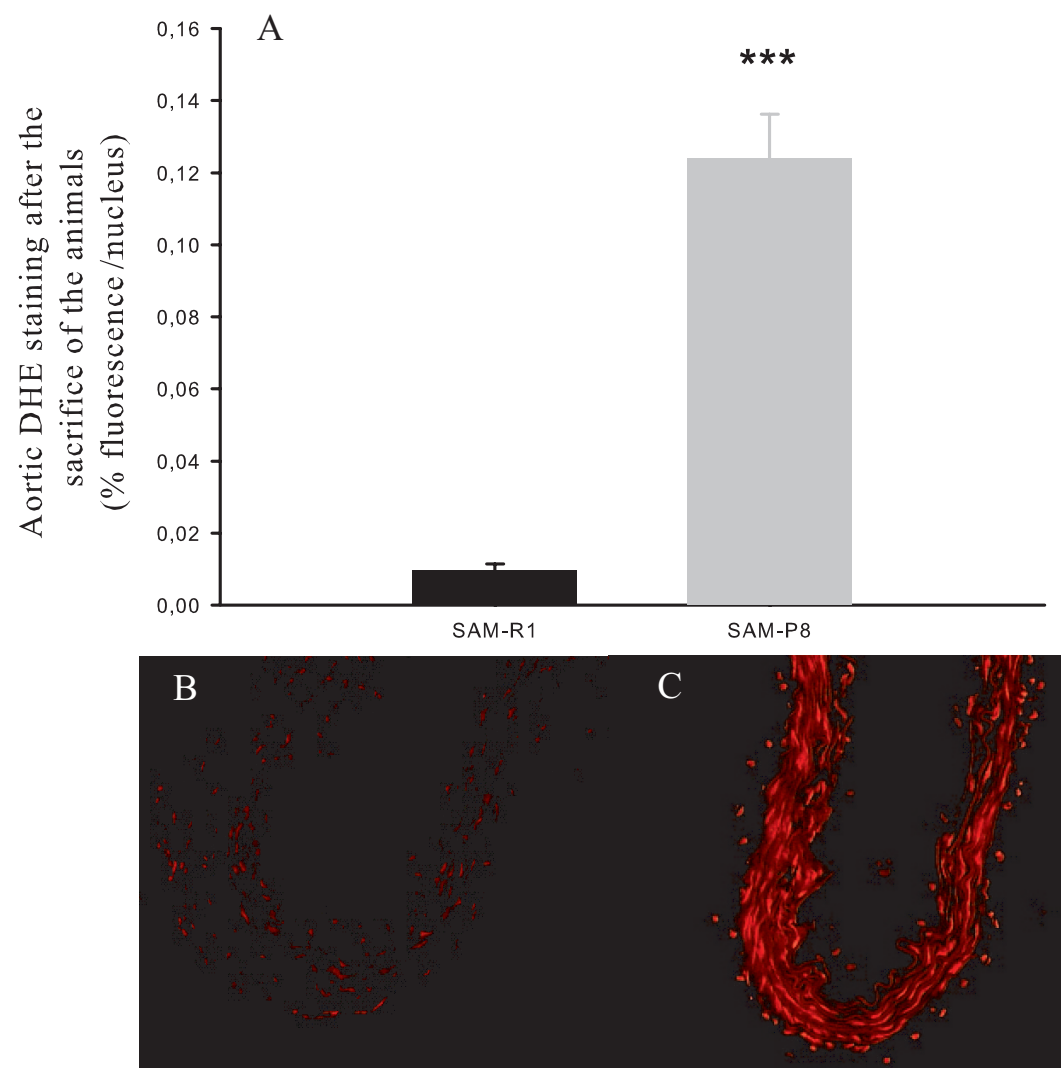


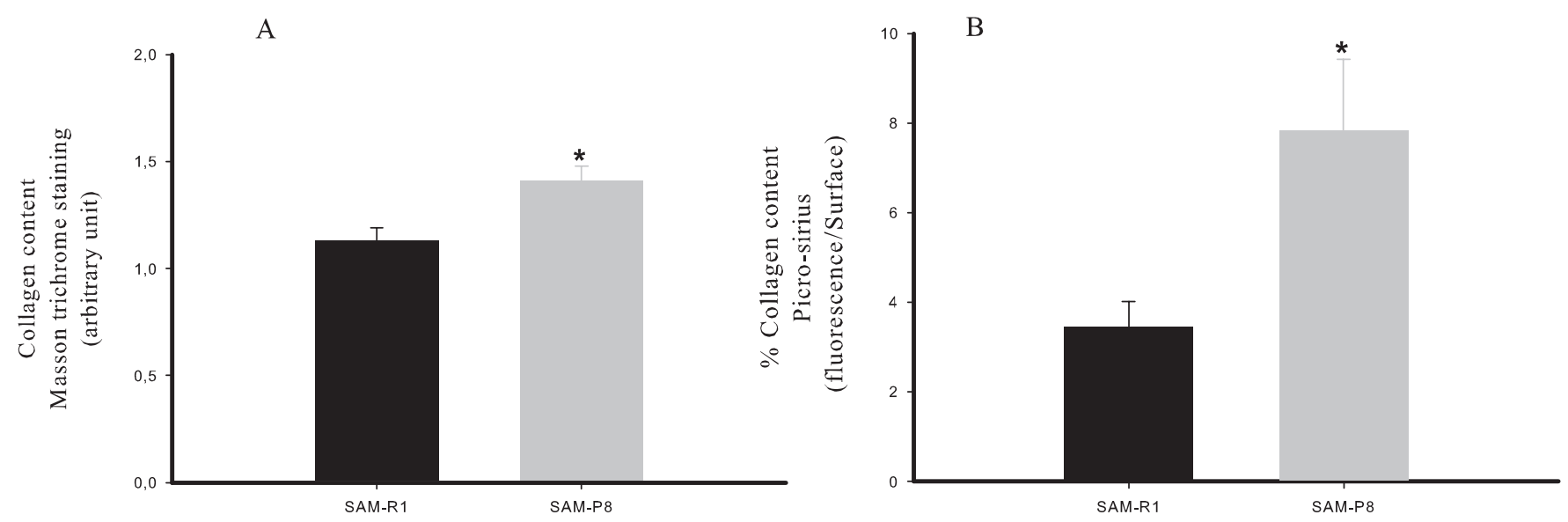

FIGURE 3. Evaluation of collagen content in aorta (A) Masson trichrome staining, the presence of collagen was scored at $\times 400$ magnification ( 0 , absence; 1 , mild; 2 , moderate; and 3, marked). Three entire sectional areas were evaluated per artery, by two blinded investigators; (B) evaluation of collagen content in frozen slices of SAM aorta. Percentage of detection of collagen per unit area was assessed with picrosirius red coloration under polarized light. All values represent mean \pm SEM, * $P$ less than 0.05 versus SAM-Rl.

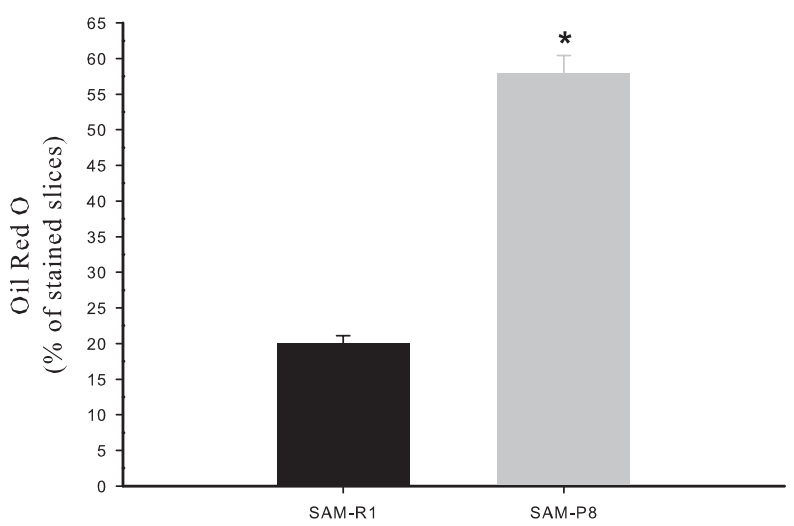

FIGURE 4. Evaluation of lipid infiltration in SAM aortas. The presence of intracellular lipid droplets was scored at $\times 400$ magnification (yes or no score). Three entire sectional areas were evaluated per artery, by two blinded investigators. All values represent mean \pm SEM, * $P$ less than 0.05 versus SAM-Rl.

67.53\% $11.79 \%$, SAM-P8 PostC: $94.69 \% \pm 3.15 \%$, SAM-R1: $86.53 \% \pm 4.77 \%$, and SAM-R1 PostC: $84.38 \% \pm 8.37 \%$.

Heart Rate

During the first $3 \mathrm{~min}$ of the reperfusion period, the hearts recovered at least $50 \%$ of their preischemic HR values in all groups, but the SAM-P8 group showed lower HRs throughout the reperfusion period. However, the differences between the groups were not significant (Fig. 5C). Further- more, hearts from PostC groups presented significantly fewer episodes of arrhythmia than did their controls $(2.37 \pm 0.27$ min vs. $0.59 \pm 0.12 \mathrm{~min}$ in the SAM-R1 groups $P<0.05$; and $2.59 \pm 0.49 \mathrm{~min}$ vs. $1.17 \pm 0.07$ in the SAM-P8 groups; $P<0.05)$.

\section{Cardiac Output}

Previous studies performed in our laboratory showed that $\mathrm{CO}$ was maintained at a value of $90 \%$ of the initial period after 90 min of continuous working perfusion. In this study, recovery of $\mathrm{CO}$ at the end of reperfusion in SAM-R1 hearts was low $(27.27 \% \pm 10.72 \%)$, but that of SAM-P8 hearts was even lower $(8.53 \% \pm 4.59 \% ; P<0.05)$.

As shown in Figure 5(B), both PostC groups were able to work within 3 min after the switch to the working mode, whereas in control groups, the hearts took longer to recover $\mathrm{CO}(13 \mathrm{~min} ; P<0.05)$. Here, at the end of the reperfusion period, PostC led to better recovery compared with controls (42.69\% $\pm 6.12 \%$ for SAM-R1 PostC vs. $27.27 \% \pm 10.72 \%$ for SAM-R1; $P<0.05$; and $39.35 \% \pm 9.58 \%$ for SAM-P8 PostC vs. $8.53 \% \pm 4.59 \%$ for SAM-P8; $P<0.05)$.

\section{In Situ Detection of Superoxide in Hearts After the} Ischemia-Reperfusion Sequence

Both SAM-R1 and SAM-P8 heart slices showed a high degree of DHE staining; PostC led to a reduction in the oxidative stress index. In the SAM-R1 group, oxidative stress was $3.24 \times 10^{-3} \pm 2.10 \times 10^{-4}$ emissions per nucleus compared with $2.62 \times 10^{-3} \pm 2.09 \times 10^{-4}$ emissions per nucleus for the SAM-R1 PostC group; $P$ less than 0.05 (Fig. 6). In the

TABLE 1. Initial cardiovascular functional parameters during isolated working heart perfusion of SAM-R1 and SAM-P8

\begin{tabular}{lccccc} 
& $\begin{array}{c}\text { Coronary flow } \\
(\mathbf{m L} / \mathbf{m i n})\end{array}$ & $\begin{array}{c}\text { Cardiac output } \\
(\mathbf{m L} / \mathbf{m i n})\end{array}$ & $\begin{array}{c}\text { Heart rate } \\
(\mathbf{b p m})\end{array}$ & $\begin{array}{c}\text { Left ventricular developed } \\
\text { pressure }(\mathbf{m m} \mathbf{H g})\end{array}$ & $\begin{array}{c}\text { Rate pressure product } \\
(\mathbf{m m} \mathbf{H g} / \mathbf{b e a t} / \mathbf{m i n})\end{array}$ \\
\hline SAM-P8 $(\mathrm{n}=17)$ & $2.74 \pm 0.20$ & $7.90 \pm 0.61$ & $333 \pm 12^{a}$ & $51.05 \pm 4.15$ & $17792 \pm 1041$ \\
SAM-R1 $(\mathrm{n}=15)$ & $2.80 \pm 0.17$ & $8.18 \pm 0.62$ & $375 \pm 13$ & $53.94 \pm 1.80$ & $20280 \pm 790$ \\
\hline
\end{tabular}

These parameters were measured at the 15 th minute of preischemic period. Values are means \pm SEM.

${ }^{a} P<0.05$. 
A
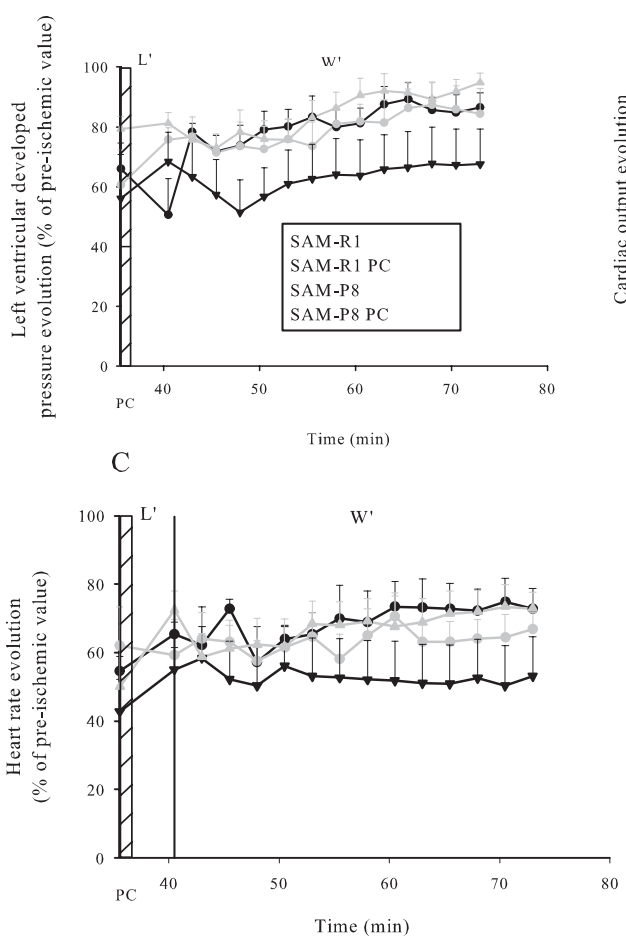

B

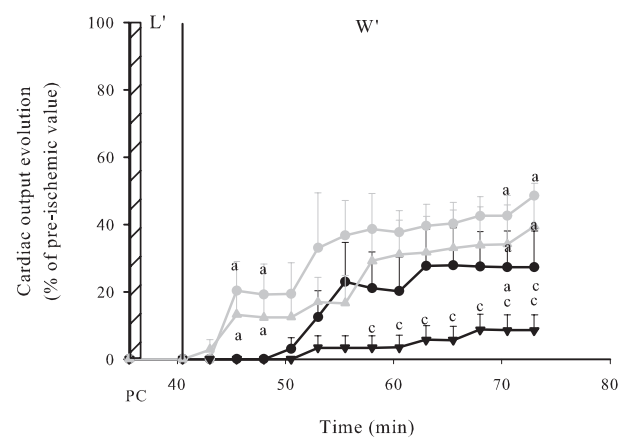

FIGURE 5. Myocardial ex vivo reperfusion results for $(A)$ left ventricular developed pressure, (B) cardiac output, (C) heart rate. Results are expressed as a percentage of the last preischemic value; $\mathrm{L}^{\prime}$, Langendorff period; $\mathrm{W}^{\prime}$, working heart period; PC, postconditioning. Values are means \pm SEM. Means at times with different letters differ: $a, b, c . P$ less than 0.05 .

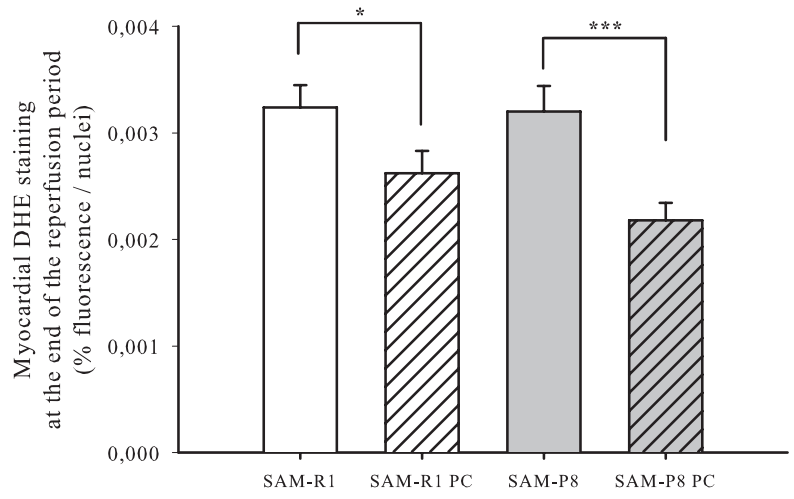

FIGURE 6. Quantification of superoxide-dependent DHE fluorescence in frozen slices of hearts subjected to 20 min of warm total ischemia and $36 \mathrm{~min}$ of reperfusion. Values are means \pm SEM. $* P$ less than 0.05 .

SAM-P8 group we found similar results with a decrease from $3.20 \times 10^{-3} \pm 2.41 \times 10^{-4}$ emissions per nucleus for SAM-P8 compared with $2.18 \times 10^{-3} \pm 1.64 \times 10^{-4}$ emissions per nucleus for the PostC group; $P$ less than 0.001 .

\section{DISCUSSION}

The SAM-P8 strain has been described for brain and immunologic aging (5). In addition, these animals present mitochondrial dysfunction with advanced age (21). We here designed a study to (1) confirm global cardiovascular aging status of these senescence-accelerated mice, (2) assess the ability of the heart to adapt to an I/R sequence, and (3) evaluate the putative beneficial effect of PostC in this context. In this study, we demonstrate, for the first time, that endoge- nous cardioprotective mechanisms are still present in SAM-P8 hearts and can be activated by a PostC protocol.

To evaluate whether SAM-P8 mice can be considered a good model of cardiovascular aging, we compared the phenotypes and biochemical parameters of SAM-R1 and SAM-P8 aortas. These analyses confirmed that SAM-P8 arteries presented an aged phenotype characterized by an increase in collagen content in the aorta. Many studies have reported that this biochemical parameter was associated with senescence (22). Furthermore, aortas of SAM-P8 mice presented an increase in lipid infiltration linked to arterial porosity that is related to the aging process (23) and increases the risk of atherosclerosis. In addition, it seems that SAM-P8 aortas presented increased production of $\mathrm{O}_{2}{ }^{--}$, again associated with the aging process. In fact, cells subjected to a long period of oxidative stress present functional deterioration (24) associated with an accumulation of subcellular damage, functional deterioration, apoptosis processes, and accelerated aging (25). Recently, we presented evidence that NAPDH oxidases are in part responsible for cardiovascular superoxide product during aging (26) and lead to increased oxidative stress.

Preischemic functional values (CF, AF, and cardiac parameters) of isolated working SAM-P8 hearts were similar to their control, SAM-R1. However, we observed a significantly lower HR in the SAM-P8 group during the preischemic period. This reduction can be attributed to the modification of adrenergic sensitivity in SAM-P8 hearts as previously described by Ferrara et al. (27) in isolated cardiac myocytes from aging guinea-pigs. In our conditions, SAM-P8 hearts were more sensitive to I/R sequences. In fact, during reperfusion, the recovery of SAM-R1 hearts was poor, but for SAM-P8, cardiac recovery was even worse. These results are in accor- 
dance with previous studies reporting that the greater sensitivity of senescent cells to ischemic insult was associated with reduced efficiency in energy production and impaired calcium flux control (28). Nitahara et al. (29) showed that isolated myocytes presented an increase in diastolic $\mathrm{Ca}^{2+}$ content with age, and an accumulation of calcium in the mitochondrial matrix accompanied by an opening of the permeability transition pore (30); these effects participate in the initiation of cell death.

The SAM-P8 strain is a murine model of spontaneous accelerated aging (5) with a lifespan of 10 months compared with 20 months for its control. Takeda et al. (31) reported that at 8 months aged SAM-P8 mice presented a higher score of senescence grading. In our study, we therefore selected 8 -month-old mice. SAM-P8 is known to have an age-related deterioration of neuronal function, but little was known about the cardiovascular system (31). A large body of correlative data demonstrates a link between aging and the accumulation of reactive oxygen species, which induces oxidative damage to macromolecules such as lipids, proteins, and nucleic acids. In our experimental conditions, the myocardial oxidative stress status was similar in both strains of mice. This finding does not support the prediction of the oxidative stress hypothesis in the aging heart. Rebrin and Sohal (32) studied the differences in the redox state between SAM-P8 and $\mathrm{C} 57 \mathrm{bl} / 6$ mice (13 months of age) and their results support the view that there were considerable variations in the reduced glutathione-to-glutathione disulfide ratio in different tissues; the ratio in the heart was similar in the two strains of mice. Concerning the putative protective effect of PostC in "senescent" hearts, our present study demonstrates that PostC, in the form of multiple brief episodes of global ischemia applied during the early minutes of reperfusion, can effectively reduce the incidence of arrhythmias and increase cardiac performance. In fact, the hearts of SAM-P8 and SAM-R1 groups presented long periods of arrhythmia during reperfusion, whereas PostC allowed the hearts to beat regularly. To our knowledge, this is the first time that a PostC protocol has been tested on senescent isolated hearts, and our results suggest that PostC is still effective on aged hearts.

Experimental studies on the restoration of myocardial function during reperfusion of ischemic hearts have suggested that the beneficial effects of PreC may be reduced by aging $(33,34)$. Human data also show that PreC has a limited cardioprotective effect in the elderly (14). However, these conclusions are not universally accepted and it has been reported that the PostC phenomenon does not seem to be progressively lost with aging (15). The effect of aging on the PostC response may thus be related to factors such as genetic strain and diseased myocardium. The PreC response was found to be conserved in aging sheep (35). The loss of the beneficial effects of PreC in aging rats was partially restored by caloric restriction or exercise training (36). This finding may be important in forthcoming investigations and comments concerning the different results.

The application of a PostC protocol in both senescent SAM-P8, and senescence-resistant SAM-R1 mice was associated with a significant reduction in superoxide production. Among the potential key players of pre- and PostC, the role of signaling reactive oxygen species has been clearly established $(18,37)$. Involvement of the mitochondrial permeability transition pore has also been supported by recent studies (38); acidosis during the first minutes of reperfusion is also an important process (39). Ischemia-reperfusion is associated with an increase in the production of free radical species (40), and the severity of the cardiac dysfunction is linked to the production of ascorbyl free radical (41). In fact, oxidative stress has been described as a major trigger of myocardial dysfunction (42).

"In contrast to PreC, PostC may have widespread clinical applications, because it can be applied during reperfusion. PostC seems to be another promising and effective tool that will provide additional opportunities for he transplantation of human hearts and overcome some of the challenges of cold ischemia and reperfusion" (17).

In conclusion, our results demonstrate, for the first time, that SAM-P8 mice present a greater degree of vascular oxidative stress and a higher susceptibility to I/R, and that this model is relevant in the study of myocardial protection in aged hearts. These animals, however, despite aging, remain sensitive to cardioprotection afforded by PostC; this protective process reduces $\mathrm{O}_{2}{ }^{-}$- production in the heart. Understanding the intimate mechanisms responsible for the activation of inner protection pathways in the SAM strain should be helpful in finding new clinical tools in the context of ischemic diseases in the elderly.

\section{ACINOWLEDGIMENTS}

The authors thank P. Bastable for English revision and gratefully acknowledge the support of the Conseil Régional de Bourgogne and the Association de Cardiologie de Bourgogne.

\section{REFERENCES}

1. Powers SK, Quindry J, Hamilton K. Aging, exercise, and cardioprotection. Ann N Y Acad Sci 2004; 1019: 462.

2. Kass DA. Ventricular arterial stiffening: integrating the pathophysiology. Hypertension 2005; 46: 185.

3. Lakatta EG. Arterial and cardiac aging: Major shareholders in cardiovascular disease enterprises. Part III: Cellular and molecular clues to heart and arterial aging. Circulation 2003; 107: 490.

4. Besse S, Bulteau AL, Boucher F, et al. Antioxidant treatment prevents cardiac protein oxidation after ischemia-reperfusion and improves myocardial function and coronary perfusion in senescent hearts. J Physiol Pharmacol 2006; 57: 541.

5. Takeda T, Hosokawa M, Takeshita S, et al. A new murine model of accelerated senescence. Mech Ageing Dev 1981; 17: 183.

6. Butterfield DA, Poon HF. The senescence-accelerated prone mouse (SAMP8): A model of age-related cognitive decline with relevance to alterations of the gene expression and protein abnormalities in Alzheimer's disease. Exp Gerontol 2005; 40: 774.

7. Takeda T, Matsushita T, Kurozumi M, et al. Pathobiology of the senescence-accelerated mouse (SAM). Exp Gerontol 1997; 32: 117.

8. Nakahara H, Kanno T, Inai Y, et al. Mitochondrial dysfunction in the senescence accelerated mouse (SAM). Free Radic Biol Med 1998; 24: 85.

9. Sureda FX, Gutierrez-Cuesta J, Romeu M, et al. Changes in oxidative stress parameters and neurodegeneration markers in the brain of the senescence-accelerated mice SAMP-8. Exp Gerontol 2006; 41: 360.

10. Zhao ZQ, Corvera JS, Halkos ME, et al. Inhibition of myocardial injury by ischemic postconditioning during reperfusion: Comparison with ischemic preconditioning. Am J Physiol Heart Circ Physiol 2003; 285: H579.

11. Galagudza M, Kurapeev D, Minasian S, et al. Ischemic postconditioning: Brief ischemia during reperfusion converts persistent ventricular fibrillation into regular rhythm. Eur J Cardiothorac Surg 2004; 25: 1006.

12. Sun HY, Wang NP, Halkos M, et al. Postconditioning attenuates cardiomyocyte apoptosis via inhibition of JNK and p38 mitogen-activated protein kinase signaling pathways. Apoptosis 2006; 11: 1583. 
13. Ebrahim Z, Yellon DM, Baxter GF. Ischemic preconditioning is lost in aging hypertensive rat heart: Independent effects of aging and longstanding hypertension. Exp Gerontol 2007; $42: 807$.

14. Bartling B, Friedrich I, Silber RE, et al. Ischemic preconditioning is not cardioprotective in senescent human myocardium. Ann Thorac Surg 2003; 76: 105 .

15. Bartling B, Hilgefort C, Friedrich I, et al. Cardio-protective determinants are conserved in aged human myocardium after ischemic preconditioning. FEBS Lett 2003; 555: 539.

16. Iliodromitis EK, Zoga A, Vrettou A, et al. The effectiveness of postconditioning and preconditioning on infarct size in hypercholesterolemic and normal anesthetized rabbits. Atherosclerosis 2006; 188: 356.

17. Koerner MM. Good news for donor hearts: Postconditioning. Transplantation 2007; 84: 1382.

18. Lauzier B, Sicard P, Bouchot O, et al. After four hours of cold ischemia and cardioplegic protocol, the heart can still be rescued with postconditioning. Transplantation 2007; 84: 1474.

19. Sicard P, Acar N, Gregoire S, et al. Influence of rosuvastatin on the $\mathrm{NAD}(\mathrm{P}) \mathrm{H}$ oxidase activity in the retina and electroretinographic response of spontaneously hypertensive rats. Br J Pharmacol 2007; 151: 979.

20. Collin B, Busseuil D, Korandji C, et al. Short-term atorvastatin treatment does not modify neointimal morphology but reduces MMP-2 expression in normocholesterolemic rabbit stented arteries. J Cardiovasc Pharmacol 2006; 47: 428.

21. Rodriguez MI, Carretero M, Escames G, et al. Chronic melatonin treatment prevents age-dependent cardiac mitochondrial dysfunction in senescence-accelerated mice. Free Radic Res 2007; 41: 15

22. Lakatta EG, Levy D. Arterial and cardiac aging: Major shareholders in cardiovascular disease enterprises. Part I: Aging arteries: A "set up" for vascular disease. Circulation 2003; 107: 139.

23. Jani B, Rajkumar C. Ageing and vascular ageing. Postgrad Med J 2006; 82: 357.

24. Ungvari Z, Csiszar A, Kaley G. Vascular inflammation in aging. Herz 2004; 29: 733 .

25. Yoon SO, Yun CH, Chung AS. Dose effect of oxidative stress on signa transduction in aging. Mech Ageing Dev 2002; 123: 1597.

26. Oudot A, Martin C, Busseuil D, et al. NADPH oxidases are in part responsible for increased cardiovascular superoxide production during aging. Free Radic Biol Med 2006; 40: 2214.

27. Ferrara N, O'Gara P, Wynne DG, et al. Decreased contractile responses to isoproterenol in isolated cardiac myocytes from aging guinea-pigs. J Mol Cell Cardiol 1995; 27: 1141.

28. Rosenfeldt FL, Pepe S, Linnane A, et al. The effects of ageing on the response to cardiac surgery: Protective strategies for the ageing myocardium. Biogerontology 2002; 3: 37.

29. Nitahara JA, Cheng W, Liu Y, et al. Intracellular calcium, DNase activity and myocyte apoptosis in aging Fischer 344 rats. J Mol Cell Cardiol 1998; 30: 519

30. Marcil M, Ascah A, Matas J, et al. Compensated volume overload increases the vulnerability of heart mitochondria without affecting their functions in the absence of stress. J Mol Cell Cardiol 2006; 41: 998.

31. Takeda T, Higuchi K, Hosokawa M. Senescence-accelerated mouse (SAM): With special reference to development and pathological Phenotypes. ILAR J 1997; 38: 109.

32. Rebrin I, Sohal RS. Comparison of thiol redox state of mitochondria and homogenates of various tissues between two strains of mice with different longevities. Exp Gerontol 2004; 39: 1513.

33. Fenton RA, Dickson EW, Meyer TE, et al. Aging reduces the cardioprotective effect of ischemic preconditioning in the rat heart. J Mol Cell Cardiol 2000; 32: 1371.

34. Tani M, Suganuma $Y$, Hasegawa $H$, et al. Changes in ischemic tolerance and effects of ischemic preconditioning in middle-aged rat hearts. Circulation 1997; 95: 2559.

35. Burns PG, Krunkenkamp IB, Calderone CA, et al. Is the preconditioning response conserved in senescent myocardium? Ann Thorac Surg 1996; 61: 925.

36. Abete P, Ferrara N, Cioppa A, et al. Preconditioning does not prevent postischemic dysfunction in aging heart. J Am Coll Cardiol 1996; 27: 1777.

37. Park AM, Nagase H, Kumar SV, et al. Effects of intermittent hypoxia on the heart. Antioxid Redox Signal 2007; 9: 723.

38. Gateau-Roesch O, Argaud L, Ovize M. Mitochondrial permeability transition pore and postconditioning. Cardiovasc Res 2006; 70: 264.

39. Cohen MV, Yang XM, Downey JM. The $\mathrm{pH}$ hypothesis of postconditioning: Staccato reperfusion reintroduces oxygen and perpetuates myocardial acidosis. Circulation 2007; 115: 1895.

40. Vergely C, Maupoil V, Clermont G, et al. Identification and quantification of free radicals during myocardial ischemia and reperfusion using electron paramagnetic resonance spectroscopy. Arch Biochem Biophys 2003; 420: 209 .

41. Vergely C, Maupoil V, Benderitter M, et al. Influence of the severity of myocardial ischemia on the intensity of ascorbyl free radical release and on postischemic recovery during reperfusion. Free Radic Biol Med 1998; 24: 470

42. Durot I, Maupoil V, Ponsard B, et al. Oxidative injury of isolated cardiomyocytes: Dependence on free radical species. Free Radic Biol Med 2000; $29: 846$. 